\title{
Gender and Orientations Toward the Future: Links to Motivation
}

\author{
Barbara A. Greene ${ }^{1,2}$ and Teresa K. DeBacker ${ }^{1}$
}

Literature on future orientation and motivation was examined for gender differences. Research revealed gender differences from five theoretical orientations: achievement motivation, future time orientation, possible selves, expectancy-value, and social-cognitive. Some of those differences seemed best explained in terms of generational differences in gender role expectations. Gender differences were found in extension and density of future goals. Men had further extension but fewer goals than women. Evidence suggested that women's future expectations have become more similar to men's in the career realm, although women also have maintained their focus on interpersonal goals. An implication is that schools are a potentially powerful sociocultural context that can encourage students to envision futures that are not constrained by gender, race/ethnicity, or other stereotypes.

KEY WORDS: achievement motivation; gender; future time orientation; motivation and sociocultural contexts.

Although much of the theory and research on motivation is concerned with short-term striving (Raynor, 1970) and proximal goals (Manderlink and Harackiewicz, 1984), there is a rich history of motivation research that examines the role of people's orientation toward the future (e.g., Gjesme, 1981a; Husman and Lens, 1999; Lens et al., 2001; Raynor, 1970). This research has provided evidence that future-oriented motivation is related to performance in the present (e.g., Gjesme, 1981a; Raynor, 1970), task engagement and persistence (Lens et al., 2001), and intrinsic motivation (Manderlink and Harackiewicz, 1984). In other words, evidence suggests

\footnotetext{
${ }^{1}$ Department of Educational Psychology, University of Oklahoma, Norman, Oklahoma.

${ }^{2}$ Correspondence should be addressed to Barbara A. Greene, University of Oklahoma, 820 Van Vleet Oval, Norman, Oklahoma 73019-2041; e-mail: barbara@ou.edu.
} 
that future orientation can be a powerful motivator of current behavior. There is also evidence, however, that future orientation can be detrimental to motivation when people are highly anxious about a future event and more motivated to avoid failure than to experience success (Gjesme, 1983a, 1996). Indeed, there are a number of ways in which the relationship between future orientation and motivation can vary as a function of individual characteristics (Gjesme, 1996).

In light of the evidence for potential benefits to intrinsic motivation and achievement from future-oriented motivation and of the evidence for individual differences, we examined gender differences in future orientation and how those differences might be linked to motivation to learn. We suspected that the same socialization forces that are believed to be responsible for sex role prescriptions and commonly observed gender differences may operate to produce gender differences in both the content of future goals and in the extent to which individuals are oriented toward the future. As Wigfield and Eccles (2002) noted, although there is evidence that sex differences in achievement have declined in recent years, there are still differences in the level of involvement of men and women in science and technology courses and careers. Therefore our goal was to examine the research-based literature for patterns of gender differences in people's representations of their futures. Our hope was that this information would help inform the design of interventions to increase the motivation to learn for both male and female students.

This review is organized around five different theoretical perspectives that have guided research on future-oriented motivation. We begin with work that established the existence of sex differences in achievement motivation and life goals. We then describe research from the future orientation perspective advanced by Gjesme (1981a) and Nurmi (1991) and from Raynor's future time perspective (FTP) expansion of achievement motivation theory (Raynor, 1970). After we review the work on sex-related differences in future time orientation (FTO), we next examine the possible selves literature (Knox et al., 2000; Marcus and Nurius, 1986). We then turn to research from the expectancy-value framework and emphasize the work of Eccles and her colleagues (e.g., Eccles et al., 1983; Wigfield and Eccles, 2002) because that work was grounded in concerns about gender that were similar to ours. The last body of research we examine is from the social cognitive perspective on motivation (e.g., Bandura, 1986). Following a discussion of the findings, we conclude with implications for educational practice. We attempted to find all of the research from these five traditions that included sex as a variable and that was reported in well-respected national and international journals, but we realize that we likely missed a few important pieces from this literature. Our intention is not to do a meta-analysis of 
sex-related differences nor is our goal to make a strong statement about sex differences. Instead, we are more interested in what the findings suggest about the larger sociocultural context in which representations of the future develop.

\section{EARLY RESEARCH ON ACHIEVEMENT MOTIVATION AND GENDER}

According to Atkinson (1974), achievement motivation is determined by the strength of a person's motive, or need, for success $\left(M_{\mathrm{S}}\right)$, the subjective probability of success $\left(P_{\mathrm{S}}\right)$, and the incentive value for achieving success $\left(I_{\mathrm{S}}\right)$ in a given situation. People high in $M_{\mathrm{S}}$ are energized to engage in activity that likely results in success, but the effects of $M_{\mathrm{S}}$ are thought to be mediated or offset by the values of $P_{\mathrm{S}}$ and $I_{\mathrm{S}}$. Similarly, the motive to avoid failure, which is based on the extent to which people experience embarrassment or shame as a result of failure, is influence by the probability of failure and the incentive value of experiencing failure in a particular setting. Achievement needs were measured in terms of responses to the Thematic Apperception Task (TAT; Atkinson, 1974). The TAT involves asking people to tell a story in response to pictures or verbal information. For achievement motivation research, the story is then scored in terms of the achievement themes it contains.

Horner (1974) discussed sex differences found in the early years of research on achievement motivation. In that early work, $M_{\mathrm{S}}$ scores of men on the TAT reliably increased in response to an experimental manipulation intended to encourage $M_{\mathrm{S}}$, whereas the scores of women were unaffected (e.g., McClellend et al., 1953, as cited in Horner, 1974). This suggested that women had a lower motive to succeed than men. In a later study, however, Lesser et al. (1963) demonstrated that the previous findings regarding differences between men and women could be explained by women not identifying with the intellectual pursuits encouraged in the TAT pictures.

In that Lesser et al. (1963) study, young women at an academically exclusive high school for female students were separated into groups of high academic achievers and low academic achievers. They found that responses differed depending on whether participants were responding to pictures of men or women. The achieving students were more likely to increase their achievement motivation scores when a woman was depicted, whereas the underachieving young women had their highest scores in response to pictures of men. This finding suggested that achievement motivation for female students is impacted by whether or not the students consider intellectual achievement to be appropriate for women. 
Horner (1974) argued that the Lesser et al. (1963) study and other similar work still did not fully explain sex-related differences in achievement motivation. She proposed that the concept of "a motive to avoid success" was needed for a more complete understanding (Horner, 1974, p. 91). She provided evidence that women show greater fear of success than men. Furthermore, Horner found that, in competitive situations involving men and women competing against one another, women with fear of success perform more poorly than women without fear of success. On the whole, Horner's work was some of the first to offer competing interpretations of sex-related differences found in the early work on achievement motivation.

Another approach to studying gender differences in achievement motivation involves examining possible differences in long-term goals or life plans. For instance, Astin and Nichols (1964) studied the life goals of high achieving male and female students. Astin and Nichols surveyed 3,830 men and 1,665 women, who were national merit scholars with high Scholastic Aptitude Test (SAT) scores, about their career plans and related life goals. Men reported more interest in careers in science and technology and more concern with attaining prestige than did women. Men also expected to make more money than women. Women reported more concern with obtaining personal comfort and becoming altruistic. There were also sex-related differences in the interactions between career and other life goals. For instance, men who said they wanted to be medical doctors reported greater concern for personal comfort than did women who said they wanted to be medical doctors. It is interesting to note that these differences reflect the sex role prescriptions of the 1960s, which are still detected today in concerns about underrepresentation of women in science and technology careers (Wigfield and Eccles, 2002).

Approximately two decades later, Fiorentine (1988) argued that the evidence found for gender differences in values, such as women valuing altruism and men valuing prestige in a career, was likely related to differences in the traditional roles of men and women. He hypothesized that, as the number of women working outside the home increased, there would be increased convergence in the values of men and women. He examined trends based on college freshmen sampled from 350 schools from 1969 to 1984 . The data showed that although women tended to show greater valuing of status, recognition, and authority over the years, they did not decrease in their valuing of altruistic pursuits. The data also showed that the educational and career goals of women changed to match their changing values. The longitudinal data additionally showed increased congruity over time between the values and plans of both men and women. 


\section{Summary of Early Research on Sex-Related Difference}

The work reviewed above suggests that achievement motivation for female students in the 1960s and 1970s might have been more constrained by perceptions of acceptable sex roles than achievement motivation was for male students. The study by Lesser et al. (1963) most clearly demonstrated this, but the work of Horner (1974) also suggested that female students' motivation for success was complicated by concerns that academic success was (or was perceived by others to be) an inappropriate goal for women. The research by both Astin and Nichols (1964) and Fiorentine (1988) suggested that the future strivings of young women involve a concern for others, for being altruistic, and for their personal careers and comforts. Compared to men, women appeared more variant in their salient life goals (Fiorentine, 1988).

\section{FUTURE TIME ORIENTATION AND FUTURE TIME PERSPECTIVE}

Although the work described above is broadly related to future striving, the next body of literature reviewed is specifically couched within the frameworks of future time perspective (FTP) and future time orientation (FTO), which directly measure people's conceptions of the future. According to Husman and Lens (1999), FTP examines how people think about the future. People are described in terms of how far into the future they typically plan, the contents of their future imaginings, and the extent to which those imaginings are realistic. These future conceptions are linked to goal setting and to other important aspects of motivation, such as perceived instrumentality (Husman and Lens, 1999). Perceived instrumentality is when a person recognizes that the current endeavor supports, or is instrumental to, achieving a valued future goal. For academic learning, recognizing instrumental situations is important for encouraging persistence in the face of challenge or boredom (see Miller and Brickman, 2004).

In contrast to FTP, which is generally thought to be multidimensional (that is, involving extension, density, and realism), FTO is viewed as a unidimensional construct that describes the stable tendency or trait of individuals to be oriented toward their future (Husman and Lens, 1999). Gjesme (1996) noted that FTO is a stable characteristic that captures "a general capacity to anticipate, shed light on, and structure the future" (p. 211) and the degree to which individuals engage in such future-oriented cognitions. Husman and Lens (1999) noted that most researchers tend to equate the concepts of FTP and FTO as capturing the "tendency to focus on and to value the future" 
(p. 115). As one reads the literature it is often impossible to discern which framework, that of FTP or FT0, is guiding a given study. Additionally, in some cases it is obvious that authors are equating the two perspectives. Therefore, in this section we review this literature using the terms used by the author but we note here that we view the body of work as falling under the broader rubric of FTO/FTP. This section begins with the work of Gjesme who has been a prolific and influential researcher in the area of FTO and motivation for more than 30 years.

\section{Research on FTO/FTP in Relation to Gender and Culture}

\section{Research on FTO, Motives for Approaching Success and Avoiding Failure, Perceived Instrumentality, and Sex-Related Differences}

Gjesme (1979) examined the FTO of male and female sixth-grade students in relation to sex, ability (divided into three levels), and achievement motivation, defined in terms of orientation toward approaching success (two levels) and toward avoiding failure (two levels). FTO was broken down into scores on involvement (e.g., the extent to which individuals think about the future), anticipation (e.g., the length of the anticipated extension into the future), occupation (e.g., the degree to which individuals are preoccupied with thinking about the future), and speed (e.g., the extent to which the future is perceived as approaching rapidly).

Gjesme (1979) found that girls were higher than boys on total FTO, anticipation, and occupation. Furthermore, for girls the highest FTO scores were associated with high scores on motive for success and with low scores on motive to avoid failure. Other variations in motives did not influence girls' FTO scores. Boys also had their highest scores on FTO when motive for success was high and motive to avoid failure was low; but, interestingly, their next highest mean occurred when both motives were low. Ability level mattered more for girls. Girls with moderate ability were higher on FTO than girls with lower ability.

In a later study of sixth-grade students, Gjesme (1983a) again examined how FTO and ability were related to orientations toward approaching success and avoiding failure and to achievement motives when the degree of perceived instrumentality of the current task was also measured. In this study, FTO was measured with a single score on items that asked about the extent of thought and concern given to the future. An interaction among sex, ability, and FTO was found for both the motive to avoid failure and the motive to approach success. Female students with low FTO and low ability had considerably higher scores on motive to avoid failure than all 
the other combinations of sex, ability, and FTO. Gjesme also found that the highest scores on motive to approach success were found with male students of moderate ability and with female students of high ability. Additionally, it was found that variation in perceived instrumentality was related to motives only for female students. For female students with an orientation toward success, achievement motivation was enhanced by the perception of instrumentality of current schoolwork. In general, the motivation of girls was more affected by differences in ability and perceived instrumentality than was the motivation of boys.

In another study by Gjesme (1983b) with sixth-grade students, worry and emotionality were the dependent variables, whereas sex, ability, FTO, perceived instrumentality, orientations toward approaching success and toward avoiding failure, and achievement motives were the individual characteristic variables. The boys again were less influenced by variation in perceived instrumentality than were the girls, who had higher worry scores when they also had lower perceived instrumentality. In general, as ability went from low to high, worry scores went from high to low. The exception to this pattern was for girls with high FTO. Girls with high FTO and high ability had the lowest scores on worry, but there was no difference in worry scores between girls of low and moderate ability. Again, girls were more affected by differences in ability and perceived instrumentality than were boys.

Gjesme (1981b) also examined factors that influence perceived goal distance (which is contrasted with actual distance in time) for male and female students in seventh, eighth, and ninth grades. He found that FTO, the importance of the goal, and perceived instrumentality were all related to perceived goal distance, but there were also gender differences. For example, with male students, when FTO was high, scores on perceived distance were lower for an important goal that was near (e.g., only a month or several months away) compared to when the goal was 1 year away. The opposite was found for female students. When FTO was high for female students, lower scores on perceived distance occurred for an important goal that was 1 year away. There were also interactions between sex and instrumentality; however, there were no gender differences when the goal was either very important or very unimportant.

More recent work by Halvari and colleagues examined FTO in the domain of sport. For example, Halvari (1991) studied gender differences in physical performance among 11- and 13-year-old students as a function of goal distance and motives to achieve success and avoid failure. He found that the motive to succeed was positively related to performance indices for both male and female students when the goal was close. For male students high on motive to succeed, there was a positive relationship between the quality of their physical performance and their FTP when the goal was 1 year off, 
whereas for female students there were negative relationships at the 1-year goal point. The most important difference was that, when the motive to avoid failure was high, female students tended to decrease their effort as the goal got closer, whereas male students increased their effort as the goal got closer. This finding suggests that male students in this sample had a more approach-oriented response to anxiety provoking situations than did female students.

In a later study that also involved FTO and motives to achieve success and avoid failure, Thomassen and Halvari (1996) examined achievement motivation, involvement in sport competitions, and the perceived instrumentality of both academic and athletic tasks among high school students. There was, again, a gender difference in regard to the motive to avoid failure. For female students, there was a negative relationship between the motive to avoid failure and involvement in sport. This pattern was not found in the male sample. In addition, for female students, there was no correlation between measures of perceived instrumentality of academic tasks and involvement in sport; but for male students there was a negative relationship. When compared to female students, male students involved in sports were less likely to perceive academic tasks as instrumental to their future goals.

Halvari and Thomassen (1997) also found a gender effect for the motive to avoid failure in their study of the sports-related FTOs of male and female high school students involved in endurance sports. Female students were higher on the motive to avoid failure than were male students. However, this was the only gender effect found.

Summary of Gender Differences Found in Research by Gjesme, Halvari, and Colleagues. It is somewhat difficult to interpret the pattern of gender differences across Gjesme's research because most of the sex-related differences found were tied to complex interactions between FTO and other student characteristics. One conclusion possibly drawn from Gjesme's results is that perceived instrumentality of an activity was more salient to female students as a motivator than it was for male students (Gjesme, 1983a,b). We could also say that ability and FTO interacted in different ways for male and female students. However, we believe that the more important implications of this work, that high FTO and perceived instrumentality are more beneficial for motivation toward success and less beneficial for motivation toward avoiding failure (Gjesme, 1996), apply to both male and female students.

Another interpretation of the findings regarding gender differences and motives to approach success and avoid failure is that female students might be more susceptible to negative performance stemming from the motivation to avoid failure. The three studies by Halvari and colleagues (Halvari, 1991; Halvari and Thomassen, 1997; Thomassen and Halvari, 1996) suggest this most clearly, but at least one of Gjesme's studies also provides evidence 
of this (Gjesme, 1983a). One interpretation of the Thomassen and Halvari (1996) finding, that female students perceived both academic and sport involvement as instrumental, is that young women are more likely to pursue goals in multiple domains. This notion is consistent with findings reported by Fiorentine (1988) and with arguments offered by Eccles (1987). This theme is repeated in some of the research discussed below.

\section{FTO Research That Examines Adolescents' Future Plans, Hopes, and Fears}

Research on future orientation has often examined the ways in which people describe what they believe the future holds for them. Typically, researchers attempt to elicit plans, hopes, fears, and expectations regarding the future from their study participants. The content and the extension in time (i.e., short or long, near or distant) of people's anticipated futures is then measured. This work, which examines sociocultural phenomena in addition to gender, is reviewed next.

Lamm et al. (1976) studied the FTO of lower and middle class West German male and female students who were 14 and 16 years old. The adolescents were asked about their future orientation in regard to the private (e.g., family), career, and public service domains. Both density (the number of hopes and fears reported) and extension (how far their thoughts extended into the future) were measured. Additionally, they examined the degree of optimism and pessimism shown by the adolescents in regard to their futures.

As predicted, in the career domain male students had greater density and extension than female students. In the family domain, female students had greater density than male students. Middle class female teens also had greater extension than their male counterparts, whereas in the lower class sample the young women had less extension than the young men. The young women also noted more hopes and fears in regard to politics and environment than did the young men. Middle class and female youths had greater density and extension in the public service domain than did lower class students. Lower class young women were more optimistic about the future than their middle class same-sex peers.

Lamm et al. (1976) suggested that the optimism of the lower class young women indicated that these young women had less knowledge of the struggles ahead of them than did the middle class young women. They wrote that concerns about balancing career and family might be more salient for the middle class women than the lower class women because the former are likely striving for more challenging careers. We believe there is an equally plausible alternative interpretation. Perhaps the lower class women were 
simply more accepting of the reality that they would have to work outside of the home, and therefore failed to interpret career striving as a conflictinvoking choice. From this perspective, being optimistic about one's future is an adaptive response to anticipated life demands, rather than evidence of naiveté.

Seginer (1988) investigated the FTO of male and female Israeli Jewish and Arab adolescents. She suspected there would be differences in FTO because the two cultures are different in that the Israeli Jews are considered "modern," whereas the Israeli Arabs are considered to be "moving toward Western-style modernity" (Seginer, 1988, p. 740). Although her study was concerned with age differences as well as those related to gender and culture, we focus only on the gender differences she found between the Jewish and Arab adolescents.

The gender differences in FTO were in the salience of concerns across different future life domains (Seginer, 1988). For Israeli Jews, male students had greater saliency in regard to military service, work, and career, whereas female students showed greater saliency in regard to marriage, family, and concern for others. There were no gender differences in specificity of goals for the Jewish sample. For the Israeli Arabs, female students were more concerned with higher education, the self, and the welfare of other people, whereas male students showed higher saliency in regard to "collective issues" such as politics and economics. On the specificity dimension, female students were more specific about hopes concerning higher education and fears concerning career and work. Male students, in comparison, were more specific about their fears related to the political and economic issues facing Israel and Arabs in Israel.

Seginer (1988) explained her findings, in part, by arguing that the Israeli women were more modern and Westernized, whereas the Arab women were still striving toward modernity and focusing on higher education as an important avenue to this modern future. We thought it was interesting that all four groups were concerned with unique issues.

In a later study of male and female adolescents from different cultural groups in Israel, Seginer and Halabi-Kheir (1998) examined the density of FTO across different life domains and compared Jewish and Druze adolescents in grades 9 and 12. According to Seginer and Halabi-Kheir, the Druze are socially and culturally similar to Arab Israelis, but-unlike the Arab Israelis-are more politically aligned with Israeli Jews. Therefore, their cultural characteristics overall are a unique mix that poses interesting questions about adolescents who are approaching adulthood.

Seginer and Halabi-Kheir (1998) obtained density scores for future hopes and fears related to both prospective life course and more existential issues, including personal issues, concern for others, and concern for the 
larger community. They found ethnic differences in both hopes and fears across the different areas of future concern. Gender effects were examined by separating out the two ethnic groups for analysis. In the Druze sample, gender differences were found in hope and fear scores. Female students had higher density scores in the domains of marriage, family, and educational pursuits, whereas the highest density scores for male students were in the areas of career and work. The male Druze students also had greater density related to fears of problems within their community. In the Druze sample there was also an age by gender interaction. The density scores of 12 th-grade female students demonstrated more concern with their future family than with their family of origin, and the scores suggest that the older females had more concern than younger females for the larger community welfare. The older male Druze students showed higher density scores, compared to younger males, in regard to higher education.

In the Jewish data, gender differences in hope and fear scores were much less pronounced than they were in the Druze sample. Although the data from the Jewish students also followed traditional gender-role patterns, those gender differences were less pronounced in their sample. In the Jewish sample, age and gender did not interact. For both male and female students, the older students were more focused on what Seginer and Halabi-Kheir (1998) call the "transition to adulthood roles" (p. 322) such as school, military service, and higher education. The focus on transition roles can be contrasted with the Druze students' focus on actual adult roles, such as marriage, family, and career. That gender was less significant in the Jewish sample suggests that gender differences may be disappearing in modern Western cultures but remaining in more traditional cultures like that of the Druze in Israel.

Seginer (2000) also studied how FTO was affected by optimism and pessimism among 11th-grade Israeli students. Her goal in this case was not to highlight gender differences but to see how future oriented motivation was potentially influenced by optimism and pessimism. However, she did find one gender difference in relation to prospective military service. Young men had higher FTO scores on exploration of and commitment to future military service than young women. Social optimism was linked to the higher exploration and commitment in the domain of military service.

Other work on FTO differences as a function of culture and gender has also looked at how far into the future people extend their hopes and fears. In a study of Australian, American, and Indian adolescents, Sundberg et al. (1983) found interesting culture by gender interactions. They found that Australian young women had the longest future time extension among women and that Australians in general had longer extensions than Americans. Indian young women had the shortest overall time extension, but Indian men had the longest among the entire sample. All the adolescents seemed aware 
of education, career, courtship, marriage, and parenting as important future events. Western men were more focused on acquisitions, whereas Western women were more focused on autonomy. This might reflect the reality that women in Western cultures typically have to work harder at attaining autonomy than do males. In India, autonomy was not a concern for either sex. Sundberg et al. noted that this makes sense in a culture in which both men and women tend to stay close to home.

In another cross-cultural study, Nurmi et al. (1994) studied FTO in Australian and Finnish youths. These adolescents described goals and hopes related to future occupation, education, family/marriage, leisure activities, and property most often and in that order of frequency. Concerns noted were most often related to future occupation, education, health, global issues, and family/marriage. Female youths in both cultures noted more goals related to future occupation and family than did men, whereas male youths noted more goals related to leisure activities and property than did women. In regard to concerns, the young Finnish women reported the most concerns related to future education, and female students in both cultures had more concerns about future occupation than did male students.

Nurmi et al. (1995) included Israeli youths in their research to investigate how developmental transitions and life/developmental tasks vary depending on societal constraints. In addition to coding future orientation for hopes and concerns related to education, occupation, and family, they looked at exploration (how often do you think about it?) and commitment (how determined are you?). The gender effect concerned how these variables related to education. Specifically, Israeli youths showed the greatest gender differences in exploration and commitment, followed by Australian youth, who also differed in exploration and commitment, and Finnish youth, who only differed in exploration. Women in all three cultures had higher levels of exploration and commitment in regard to education when compared to men. Finnish and Israeli women expressed more hopes and concerns related to future education than did men from those countries.

In an earlier study, Nurmi (1987) examined the influence of home culture, defined in terms of emotional climate, on FTO of Finnish high school students. He found interesting age by gender interactions in FTO from interviews with male and female students in three different age brackets about their hopes and fears related to their futures. Regardless of home culture, female students in the two oldest groups had more hopes related to relationships with parents and more plans related to having a future family than either younger female students or male students of all ages groups. Young women in the oldest group also reported fear of war more frequently than participants in any of the other groups. For male students, emotional climate in the home interacted with fears for their future profession. Male students 
reporting a positive emotional climate were less likely to report fears than those reporting a negative emotional climate. For future emotional expectations, male students in the younger group saw the future in a more negative light than did female students of the same age. Nurmi concluded that the sex differences that did exist were more pronounced with the older students, suggesting that sex differences increased with age.

Although assessing emotional climate was one way to examine the influence of family on FTO, Nurmi and Pulliainen (1991) approached the influence of family in a different manner in their study with 11- and 15-year-old male and female Finnish students. They sought to determine whether parental behavior influences FTO differently depending on whether it arose from authoritarian control or family discussions. The findings were based on interviews with the adolescents regarding their hopes, goals, aspirations, and their interactions with parents. Hopes for a future family were positively correlated with frequency of family discussions for both male and female students, although female students more often reported hopes for a future family. Female students also mentioned more hopes related to leisure than did male students. Male students extended further into the future than did female participants, and there was a positive correlation between parental control and future extension. This relationship was not found for female students.

In a recent study, Nurmi and Salmela-Aro (2002) examined how depressive symptoms and work status might impact the development of goals for young adults making the transition from school to work. Finnish young adults were measured on depressive symptoms, personal goals, and work status over three time periods. Only one sex-related difference was found. At time two, men's self-related goals were predicted by having been unemployed at time one, whereas women's self-related goals at time two were predicted by having been underemployed (or employed in something unrelated to their prior education) at time one. Importantly, the general pattern of relationships was similar for men and women in this sample.

The work described thus far in this section on FTP/FTO was largely done by Nurmi or his colleagues and involved high school students as participants. All of the work examined gender in interaction with other sociocultural variables. The last three studies reviewed in this section focus more exclusively on gender differences in FTO among college students.

Zaleski (1987) examined goal importance, expectancy, and conflict among men and women in a university setting. The behavioral variables of interest were effort and persistence. He additionally looked at satisfaction related to goal striving. The variables were examined in relation to goals that were a week away, a month away, a year away, 10 years away, and over one's lifetime. 
Expectancy was positively related to all three of the dependent variables. Conflict was most problematic for effort but also problematic for satisfaction. Importance was critical for both effort and satisfaction. Reported goal importance was slightly higher for women than men. More variance in persistence was explained for men when the goal became more proximal, but the opposite was true for women (Zaleski, 1987). This suggests that once women set long-term goals they are persistent in their attempts to reach those goals. Men appear more persistent when they are pursuing short-range rather than long-range goals. This is consistent with the finding by Gjesme (1981b) that girls with high FTO had lower perceived goal distance with a more distant goal, and the finding by Halvari (1991) that women decreased their goal striving as goal attainment approached whereas men increased their goal striving.

Greene (1990) used structured interviews with high school and college students to examine density, spontaneous extension, and constrained extension of expected future events. Previously devised event codes were used to capture future goals in four major categories: achievement, relational, experiential, and existential. Men and women did not differ on the density variable. They had similar numbers of expected events, but male students projected further into the future than female students and were more likely to suppose that their events would be evenly distributed throughout their future lives. Female students put as much emphasis on future professional and material achievement as did male students, but they were more likely to expect a 5-10-year break in their careers for raising children. A general finding was that among the older adolescents, men and women had similar life course expectations, and their expectations more often conformed to cultural norms when compared to younger adolescents.

Greene and Wheatley (1992) compared college and noncollege men and women in terms of their future expectations for the self. They found that male students extended further into the future than did female students. Although men and women reported similar numbers of future events, women mentioned more family-related future events than men. They also found that for women, but not for men, extension in the distant future was related to reasoning ability and lower levels of current feelings of distress.

The major gender difference reported by Greene and Wheatley (1992) was that women anticipated future adult transitions in closer proximity to the present and in closer proximity to one another. Men anticipated that employment would closely follow education but then projected marriage into the more distant future and parenthood further removed from marriage compared to women. In other words, women anticipate a number of major life events happening in a relatively brief window of time, whereas men anticipate a more relaxed trajectory of future events. An implication of these 
findings is that feelings of distress, which were higher for women, might be related to anxiety about the need to accomplish many major adult goals in a short period of time. The finding that less distress was related to greater extension adds support to this conclusion.

\section{Summary of Research on FTO/FTP in Relation to Gender and Culture}

Several conclusions can be drawn from the literature reviewed in the previous section. The cross-cultural work reviewed tends to support the assertion by Nurmi et al. (1995) that people's FTPs are shaped by the constraints that their cultural circumstances impose on them. All of the studies that examined sociocultural variables in addition to gender (e.g., SES or class, family interactions, and cultural differences) found interactions. Seginer's studies (Seginer, 1988; Seginer and Halabi-Kheir, 1998) show that gender differences, which themselves are culturally derived, are further impacted by cultural differences within a society such as Israel. Although the FTP patterns for male and female Israeli Jews looked similar to those patterns found in other western societies, they were indeed quite different for male and female Israeli Arabs. Cultural factors do, as the research just reviewed demonstrates, impact the content and extension of people's FTO/FTP.

Other gender differences are inferred from the findings reviewed in this section. First, women have more varied content in their representations of the future than do men, but men have their fewer goals more evenly dispersed throughout their FTP. In general, female students imagined their futures in terms of combinations of higher education, career, family, and leisure activities, whereas male students imagined only one or two pursuits for their futures.

Both men and women have both strengths and potential weaknesses in their FTOs. Interestingly, the weakness in the FTO of each gender could be off-set by adopting the aspects of the other gender's FTO that are associated with strength. For example, male students could benefit by increasing the variety of domains reflected in their FTO. A greater diversity of goals would likely enhance resiliency in the event that one goal pursuit is derailed or delayed. Female students, on the other hand, would likely benefit from increasing the extension in time of their FTOs and the dispersion of goals within their FTOs.

In sum, there are patterns of differences found when the FTOs of men and women are compared. Moreover, other sociocultural variables add to the complexity in those patterns. As seen in the next section on possible selves, culture not only impacts people's views of what they will be doing and when, but also of who they think they will be in the future. 


\section{RESEARCH ON POSSIBLE SELVES}

Marcus and Nurius (1986) proposed that people develop and maintain representations of themselves in the future. These mental representations are thought to contain both desired future selves and feared future selves. To the extent that we value and desire the positive or hoped-for possible selves, we should adjust our behavior to increase our chances of realizing those selves. To the extent that we are repelled by the negative or feared possible selves, we should devise behavioral patterns that decrease our chances of realizing those feared selves. In other words, the choices we make in the present are based on our desire to develop toward the person we hope to become and away from the person we fear becoming. In this section, we first look at some of the work on possible selves that is not tied to academic learning, then we present the work that has linked possible selves to academic motivation and achievement.

Knox et al. (2000) studied gender differences in the possible selves of high school students. The participants completed the Hoped-For Possible Selves Questionnaire and the Feared Possible Selves Questionnaire. They also rated the extent to which they thought they would experience particular possible selves and the affective saliency of the possible selves.

Knox et al. did not find gender differences related to the number of hoped-for or feared possible selves; however, they found that female students had higher ratings of saliency on their hoped-for self and higher ratings of likelihood on the feared self compared to male students. There were also differences in the category frequencies of possible selves. For hoped-for possible selves, the young men noted occupations first, then relationships, whereas for young women it was the other way around. For feared possible selves, young men noted physical illness and/or death and general failure. For young women, the most feared possible selves were related to relationships and then physical illness and/or death.

Segal et al. (2001) examined the Anticipated Life History (ALH) narratives of students attending a 4-year college and a community college for information related to future possible selves. The narratives were scored to yield measures of the following five characteristics of possible selves: psychological complexity, life role complexity, mutuality of relationships, resolution of conflicts, and altruism.

Consistent with the recent work described in previous sections, Segal et al. (2001) found that women had more words in their narratives about relationships, but men and women were the same in the number of words about future careers and work life. Although there were a number of other life events that were similar for male and female college students, women were more likely to include the following life events in the narratives of their 
possible futures: career, marriage, children, divorce, and death of a spouse. The authors also found that the gender variable reliably predicted scores on psychological complexity, life role complexity, and resolution of conflicts with women scoring higher on each dimension. Segal et al. also reported differences between the samples of college students. Women in the 4-year college sample were higher on the psychological complexity measure than women in the community college sample. Men in the 4-year college sample were higher on the career measure than men in the community college sample.

Instead of examining gender as the sociocultural variable, Kao (2000) examined the influences of stereotypes about racial and ethnic groups on the possible selves of adolescents from different groups. Kao conducted focus groups and personal interviews with high school students who were either Asian, Black, Hispanic, or White. She elicited from the students their views on their group's and the other groups' academic performance. She found that the Black, Hispanic, and Asian students were aware of stereotypes about their academic performance (or their job prospects, in the case of Hispanics), and that this awareness was reflected in their possible selves. For instance, Black students focused most on how to avoid the stereotype of school failure, which Kao argued was their feared possible self. Asians, on the other hand, focused most on meeting high expectations for academic success, a positive possible self. The Hispanic youths were more concerned about avoiding a life of manual labor, as that was the feared possible self thought to be consistent with the stereotype associated with Hispanics. These findings strike us as consistent with the other findings, including gender effects, indicating that future orientations are shaped by the constraints the dominant culture imposes on the possibilities imagined by adolescents (e.g., Nurmi et al., 1995).

Day et al. (1994) conducted a study in which they attempted to change the imagined possible selves of Mexican American elementary students so that their possible selves would less likely reflect negative stereotypes about current academic selves and future occupational selves. They also wanted to see whether the possible selves intervention would help students see a contingent path between the current academic self and the future self.

Day et al. (1994) found that students did tend to change their possible selves to include some of the nonstereotyped careers that they were exposed to during the intervention. They also showed increased knowledge of how to be a good student and how academics are linked to future success. Genderstereotyped occupations as hoped-for possible selves were also found. Both before and after the intervention, female students were more likely than male students to note nurse and teacher as hoped-for possible selves, and 
male students were more likely than female students to note police officer as a hoped-for possible self.

Markus and her colleagues conducted several studies that provided support for links between possible selves and academic performance. For example, Ruvolo and Markus (1992) examined how the possible selves of college women were related to their performance on cognitive tasks. Across three studies they found that having a possible self that included success was related to performance on the tasks. Cross and Markus (1994) examined how self-schemas for present day problems and possible selves worked together to enhance or hinder problem solving performance. Their data supported the interpretation that possible selves provide the positive self-concept needed to negotiate the contingent path from the present self-schema to the strategies required for being effective on the task.

Lips (1995) also examined self-schemas for current and possible selves and studied how these operated in relation to the math/science domains. She found that college women who identified themselves with math/science domains were more likely to take courses in those domains and were more likely to identify with attributes characteristic of those domains (e.g., analytical, bright, mathematical, systematic), even if they did not yet have extensive experience in the domains. In a second study, Lips found that male and female college students did not differ on the assessment of self-schema for math/science assessment, meaning that men and women were relatively equally distributed into positive and negative self-schemas for math/science. She found that positive self-schemas were again related to course enrollment and that confidence in selecting a career involving math/science was related to having a positive self-schema. This study, like the work of Cross and Markus (1994), suggests how current and future self-schemas might relate to one another, though Lips did not directly measure possible selves.

Finally, Anderman et al. (1999) studied relations between the current and future academic and social selves of seventh-grade students and changes in grade-point average (GPA). GPA was predicted from both present-self indices of academic and social self-concept and future-self indices of academic and social self-concept. They found that the best predictors of present-self GPA were having a current positive academic self-concept and being female. The best predictors of future-self GPA were positive academic future self and being female.

\section{Summary of Research on Possible Selves}

When gender differences were found in research on possible selves, the pattern of differences was consistent with the work from the FTO/FTP 
frameworks. In the studies where participants reported the nature of their possible selves, female students were more likely to emphasize interpersonal relationships than were male students (Knox et al., 2000; Segal et al., 2001). Additionally, Segal et al. found that women had more complexity in their possible selves. This is consistent with previously discussed findings (e.g., Fiorentine, 1988; Thomassen and Halvari, 1996). The research on race and ethnic group differences in possible selves was also similar to findings from the FTO literature. The data strongly suggest that people's representations of themselves in the future are influenced by culturally determined perceptions of what is expected of them based on gender and/or racial/ethnic membership. However, Kao (2000) demonstrated that sometimes adolescents view the stereotype as a challenge to overcome rather than a limitation to accept.

Gender differences were much less clear in the academic domain of possible selves. Perhaps gender is not a variable that encourages or discourages positive academic future selves. We agree with Anderman et al. (1999) that there has been little work on how possible-self variables are related to academic motivation and achievement. The work of Markus and her colleagues is the exception. A theory that has extensively examined future-oriented variables in relation to academic motivation is the expectancy-value theory (Eccles, 1984; Eccles et al., 1983; Wigfield and Eccles, 2002).

\section{EXPECTANCY-VALUE THEORY}

Eccles and colleagues have used an expectancy-value framework to study the influence of psychological and developmental factors on academic task choice and performance. In their model, an orientation toward the future is incorporated in the construct of expectancy and in their conceptualization of values, particularly attainment and utility value (Eccles, 1984; Eccles et al., 1983; Wigfield and Eccles, 2002). Expectancies are influenced by past achievement outcomes but also by the individuals' interpretation of past outcomes, perceived ability for the task, and perception of the task, particularly task difficulty. Expectancies are related to task choice and performance in a number of achievement domains including mathematics (Eccles, 1984; Eccles et al., 1983; Feather, 1988; Greene et al., 1999; Meece et al., 1990), science (DeBacker and Nelson, 1999, 2000; Greenfield, 1997; Kahle et al., 1993; Nolen and Haladyna, 1990; Sullins et al., 1995), English (Eccles et al., 1983, 1993; Feather, 1988; Wigfield et al., 1991, 1997), instrumental music and sports (Eccles et al., 1983, 1993; Wigfield et al., 1991, 1997).

Research has yielded somewhat inconsistent findings of gender differences in expectancy for success. Early studies showed female students had lower expectancies of success than male students across a variety of age levels 
and in regard to a diversity of tasks (Frieze et al., 1978). More recently, studies in the math domain showed male students had higher perceived ability or self-efficacy (both variables being proxies for expectancy) than female students (Eccles, 1984; Eccles et al., 1983, 1993; Miller et al., 1996; Pajares, 1996; Wigfield, 1994; Wigfield and Eccles, 1992). Greene et al. (1999) found that, in required math classes, male students had higher perceived math ability than female students, but this was not true in elective math classes.

A number of studies found gender differences in perceived ability in science (Catsambis, 1995; DeBacker and Nelson, 2000; Kahle and Lakes, 1983; Lee and Burkam, 1996; Simpson and Oliver, 1990; Steinkamp and Maehr, 1984; Weinburg, 1995). Moreover, Sullins et al. (1995) found that expectancy variables discriminated between biology majors and nonmajors for women, but not for men; and predicted intent to enroll in future courses for women, but not for men. Investigations that included the domains of mathematics, English, sports, and instrumental music showed gender differences in perceived ability and perceived task difficulty in line with gender stereotypes regarding these domains; that is, male students had higher expectancies than female students in math and sports, whereas female students had higher expectancies than male students in English and music (Eccles et al., 1983, 1993; Wigfield et al., 1991, 1997). These gender differences were detected as young as the first grade, and appeared to increase with age.

Some studies indicate that female students have lower expectancies for success than male students on novel tasks (Dweck and Bush, 1976; Dweck and Gilliard, 1975; Frieze et al., 1978; Parsons and Ruble, 1977), but not on familiar tasks (Frieze et al., 1978; Kimball, 1989; Parsons and Ruble, 1977). When researchers attempted to distinguish between generalized expectancies (e.g., will you do well in your next math class?) and specific expectancies (e.g., will you do well on the math test on Friday?), female students scored lower on generalized expectancies but not on specific expectancies (Frieze et al., 1978). Similarly, Eccles et al. (1983) reported no gender differences in expectancies for success in the current math class, but found that male students had higher expectancies than female students for success in future math classes.

Gender differences were found in regard to all three aspects of valuing proposed in the expectancy-value model (Eccles et al., 1983; Eccles and Wigfield, 1995). Some evidence indicates that, as early as the middle school years, male students perceived math courses as being greater in utility value than did female students (Fennema and Sherman, 1977, 1978). This was found for both basic and advanced mathematics courses (Eccles et al.,1983). Moreover, male students rated future goals as more important in their decisions to enroll in mathematics courses than did female students, implying greater perceived utility value of math (Eccles et al., 1983). Feather (1988) 
found gender differences in subjective valuing of math and English among college students. Using a measure of value that included aspects of attainment, utility, and intrinsic value as described by Eccles et al. (1983), he found that men reported higher valuing of math, and women reported higher valuing of English.

Using a measure of subjective valuing that tapped attainment and utility value, Eccles and colleagues (Eccles et al., 1993; Wigfield et al., 1997) reported gender differences in subjective valuing of reading, instrumental music, and sports in children as young as first grade. Girls were higher in subjective valuing of reading and instrumental music, whereas boys were higher in subjective valuing of sports. These differences were in line with sex role stereotypes and were stable over a 3-year time period. Interestingly, these investigations did not find gender differences in subjective valuing of mathematics. Similarly, no gender differences in utility, attainment, or intrinsic value were found in studies of high school students enrolled in math (Greene et al., 1999) or science (DeBacker and Nelson, 2000) classes.

In an investigation of course enrollment patterns, Eccles (1984) found that subjective task valuing mediated gender differences in both intention to take advanced courses in English and math, and in actual enrollment in advanced math courses. It appears that, for young men, task valuing is more closely related to performance history than it is for young women. For example, among young men, past performance was the sole predictor of enrollment in advanced math classes. Among young women, past performance predicted enrollment in advanced math classes, but subjective task valuing was a second important unique predictor. Female students who valued math were more likely to enroll in advanced math classes regardless of performance history than those who did not value math. Feather (1988), using path analysis, found that subjective valuing of English mediated the relationship between sex of students and enrollment in English courses. Similarly, valuing of math mediated the relationship between sex of student and enrollment in math courses, although the mediating role of perceived math ability was greater.

\section{Summary of Research on the Expectancy-Value Model}

As noted, the expectancy-value model includes two separate constructs that are characterized, at least in part, by an orientation to the future. These are expectancies for success at a task and perceived value of the achievement domain. The research literature reveals a record of gender differences in relation to these constructs. These gender differences appear to parallel 
changes in sex role stereotyping that have occurred at a societal level over the past several decades.

Boys and men often have higher expectancy for success than girls and women, although this may be partly explained by historical conceptions of gender roles and by the particular sex role stereotype attached to the achievement domain. Studies conducted in the 1970s showed a general pattern of lower expectancies in female students, regardless of age or achievement domain (Frieze et al., 1978). Work done later in the 1980s and 1990s revealed a somewhat different pattern, reporting higher expectancies for men in malestereotyped achievement domains such as math (Eccles, 1984; Eccles et al., 1983, 1993; Miller et al., 1996; Pajares, 1996; Wigfield, 1994; Wigfield and Eccles, 1992), science (DeBacker and Nelson, 1999, 2000; Greenfield, 1997; Kahle et al., 1993; Nolen and Haladyna, 1990; Sullins et al., 1995), and sports (Eccles et al., 1983, 1993; Wigfield et al., 1991, 1997), and reporting higher expectancies for women in female-stereotyped achievement domains such as English (Eccles et al.,1983,1993; Feather, 1988; Wigfield et al., 1991, 1997), and music (Eccles et al., 1983, 1993; Wigfield et al., 1991, 1997).

In addition to the probable mediating role of gender stereotypes in these findings, methodological features of the investigations perhaps influenced whether gender differences were found. For instance, evidence suggests that women's reports of expectancy of success are influenced by the novelty/familiarity of the achievement task (Dweck and Bush, 1976; Dweck and Gilliard, 1975; Frieze et al., 1978; Kimball, 1989; Parsons and Ruble, 1977) and by the specificity/generality of the context about which they were reporting expectancies (Eccles et al., 1983; Frieze et al., 1978). To the extent that studies presented female students with novel tasks, or asked about relatively generalized expectancies, girls' and young women's expectancies of success may have been underestimated.

The pattern of gender differences in subjective valuing also parallels historical changes in sex role conceptions. Findings that male students value math more than female students were published in the 1970s and 1980s (Eccles et al., 1983; Feather, 1988; Fennema and Sherman, 1977, 1978). In the 1990s researchers were still reporting differences that reflected genderstereotyped attitudes about some achievement domains, with girls/young women reporting higher valuing of English, reading, and music, and boys/ young men reporting higher valuing of sports (Eccles et al., 1993; Wigfield et al., 1997). The most recent investigations, however, were no longer reporting gender differences in valuing of math (Eccles et al., 1993; Greene et al., 1999; Wigfield et al., 1997), or of science (DeBacker and Nelson, 2000).

To the extent that gender differences exist in values, task choices, and achievement, Eccles (1984, 1987; Eccles et al., 1990; Wigfield and Eccles, 2002) has argued that they are related to gender role socialization. Different 
socialization experiences are thought to lead boys and girls, men and women, to hold different values and different value hierarchies. Because of these differences in values, male and female students differ in the extent to which they ascribe attainment and utility value to particular activities and tasks. These differences in values are thought to lead to differences in task choice and performance outcomes.

\section{SOCIAL COGNITIVE RESEARCH ON PERCEIVED INSTRUMENTALITY}

Expectancy-value theory incorporates a future orientation in the guise of values. In social cognitive theory, future orientation is embodied in the notion of perceived instrumentality. Social cognitive theory (Bandura, 1986; Schunk, 1989) seeks to explain human behavior in terms of goals, expectations, and outcomes. Most of human behavior is thought to be goal directed. Actions that are believed to move the individual closer to a personally relevant goal, and that result in favorable outcomes, are likely to be performed. Actions that are believed to interfere with goal attainment, or that result in unfavorable outcomes, are likely to be avoided.

As noted throughout this review, a number of theorists have suggested that personally valued future goals play an important role in motivation by adding self-relevant incentive value to the current task (e.g., Marcus and Nurius, 1986; Miller and Brickman, 2001, 2004; Nuttin, 1985; Raynor and Entin, 1982). Our focus in this section is on the research on gender differences found in future goals or in perceived instrumentality, which has been conducted within the framework of social cognitive theory.

In empirical studies of the role of future goals in achievement motivation, essentially the same construct has variously been referred to as future consequences (Miller et al., 1996), perceived instrumentality (DeBacker and Nelson, 1999, 2000; Husman and Lens, 1999; Miller et al., 1999; Van Calster et al., 1987), or future goals (Greene et al., 1999). We prefer the term perceived instrumentality because it most closely communicates what the scales used in these studies are actually measuring. Items used in these investigations ask students to report the extent to which they perceive the current task or learning context as instrumentally related to a future goal. Note that students are not asked what particular future goal(s) they are pursuing. In the review that follows, we consistently use the term perceived instrumentality to refer to this construct.

Findings are fairly consistent in regard to sex differences in relationships between perceived instrumentality and achievement tasks in that, in three out of four studies, women scored higher on instrumentality scores. Greene 
et al. (1999) reported that female high school students had higher scores on instrumentality than male students in both required and elective math classes. Similarly, Miller et al. (1996) reported higher instrumentality scores for female high school students. DeBacker and Nelson (2000) reported that female high school science students had higher scores on instrumentality than males. On the other hand, DeBacker and Nelson (1999) did not find gender differences in instrumentality among high school science students.

In the science domain, instrumentality was related to cognitive strategy use for male students but not for female students, and related to a measure of general effort for female students but not for male students (DeBacker and Nelson, 1999). Path analyses, modeling the relationship between instrumentality and both math achievement and reported effort, revealed no gender differences (Greene et al., 1999). Perceived instrumentality mediated the relationship between perceived ability and both math achievement and reported effort for both men and women. Similarly, in a study of the predictive relationships between goals and achievement outcomes, Miller et al. (1996) found that although perceived instrumentality was an important additional predictor of self-regulation, effort, deep strategy use, and achievement after learning and performance goals, there were no gender differences in regard to these relationships.

\section{Summary of Research From the Social Cognitive Perspective}

It is difficult to discern a clear pattern in regard to gender differences on the basis of the studies just reported. We resist writing off these inconsistent findings as artifacts of imprecise measurement, developmental change, or cohort effects because there was a fair degree of consistency in how instrumentality was operationalized and measured, because the age of students was similar across studies, and because data were collected for the various studies within a relatively narrow window of time. More work is needed to determine whether there are systematic gender differences in the perceived instrumentality of various academic tasks and domains, and what other variables may be influencing gender differences.

\section{CONCLUSIONS}

The work reviewed here illustrates that orientation to the future is conceptualized and measured in a number of different ways by different researchers. In all of these forms, conceptions of the future were found to play an important motivational role in regard to current strivings. Additionally, across all five theoretical perspectives, gender differences were found. 
One main conclusion that is drawn from the research from all five frameworks is that the contents of people's imaginings of the future are strongly influenced by sociocultural factors, such as sex role prescriptions and other norms and expectations that mark the particular context in which one lives. Research findings indicate that the future imaginings of men and women differ in ways that reflect the nature of sex role stereotypes that predominated at the time and place the research was conducted. There is also evidence that peoples' future orientations reflect the roles and possibilities defined for them by their culture. We believe the research reviewed here shows the importance of studying differences in FTP as they are embedded in the larger sociocultural context.

In regard to gender differences, evidence from a variety of research traditions suggests that women pursue a greater diversity of goals compared to men. This finding probably reflects the change in women's roles that has marked Western societies in recent decades. Women continue to hold goals for marriage and family, yet it is also commonplace for them to pursue goals related to employment or a career, especially in modern Western cultures. In contrast, societal expectations for the male role have changed less dramatically and this may explain, in part, why men remain heavily focused on sex-typed goals related to employment and financial security.

The potential advantage of simultaneously pursuing multiple goals across a variety of domains is that it may offer a certain amount of resiliency in the face of blocked or frustrated pursuit of individual goals. For men, who may be pursing a smaller number of goals that cluster within a smaller number of domains, there is higher risk that some or many of their salient goals will be simultaneously blocked, leaving men more psychologically vulnerable. As we argued earlier, if men were to increase the number of domains in which they are pursuing goals, they might experience greater resiliency in the face of life's inevitable setbacks.

On the other hand, from our review it appears that men have an advantage in that they perceive a longer time frame for achieving their major life events when compared to women. Women might be at risk for experiencing more conflict among their goals due to perceiving a relatively short time frame within which a number of major life goals must be attained. It is likely that women would benefit from increasing their anticipated time frame for achieving their life goals. We suspect that one explanation for the finding of female students being more likely to withdraw from goal pursuit when attainment is near (Halvari, 1991; Zaleski, 1987) is the anxiety of coping with simultaneous major life events. In addition, the motivation of girls and women seems more impeded by negative affect related to fear of failure compared to the motivation of boys and men (Gjesme, 1983a; Halvari, 1991; Halvari and Thomassen, 1997; Thomassen and Halvari, 1996). It is possible 
that fear of failure increasingly impedes motivation as goal attainment draws near. In fact, we suspect that both of these explanations hold for different individuals.

In an attempt to integrate the findings discussed in this review and propose educational implications, we suggest that future orientation impacts achievement motivation in the following manner. Task engagement is critical for academic achievement. Perceived instrumentality enhances the likelihood that students will become engaged in academic tasks (Miller et al., 1999). The more future goals learners identify with, and the more clearly those goals are articulated, the greater the potential for enhanced engagement through the influence on perceived instrumentality (Miller and Brickman, 2004).

Teachers and other significant adults can play an important role in the personal development of students both by helping them envision a variety of future goals and/or possible selves, and by helping them recognize contingent paths between future goals and current tasks. We believe it is important to recognize that schools are a potentially powerful sociocultural influence on pupils. As such, schools can encourage students to envision future selves that are not constrained by stereotypes associated with gender, race/ethnicity, or socioeconomic status. By challenging stereotypes in imagined future selves, while also supporting students' expectancies for success, schools can help learners develop more goals across a variety of domains, thus creating more opportunities for adding incentive value to school tasks. Moreover, we believe that to the extent that learners imagine positive future selves across a variety of domains, they are more likely to experience both increased resiliency and a more full and rewarding life.

Perceived instrumentality is dependent upon recognition of the contingent relationships between current school tasks and valued future goals. Teachers can help students see instrumental connections between current schoolwork and future occupations to enhance their motivation to learn. We believe it is also important to encourage students to develop rewarding hobbies and interests, as these can add incentive value to current academic tasks as well. We recognize that schoolwork is not always intrinsically motivating for some learners. Educators can enhance the possibility that students identify with academic tasks by helping them to develop clear and realistic future goals across a variety of domains, to clearly envision pathways to goal attainment, and to see that current tasks bear an instrumental relationship to one or more future goals (Bandura, 1986; Miller and Brickman, 2001, 2004). In this way, more students will more often make the self-determined choice to strive toward academic achievement.

Given the evidence that socialization influences conceptions of the future, we are optimistic about the potential efficacy of motivation 
interventions aimed at helping learners develop clear and realistic future possible selves. We believe that future research efforts should focus on these types of interventions. For instance, we need more research on how to encourage and support children and teens in developing challenging yet realistic future goals. We also need research on how to help students recognize contingent paths to valued future goals and to develop concrete, realistic, and yet flexible plans for goal attainment. We also need more work examining the consequences of students becoming committed to future goals that are unlikely to attain.

\section{REFERENCES}

Anderman, E. M., Anderman, L. H., and Griesinger, T. (1999). The relation of present and possible academic selves during early adolescence to grade point average and achievement goals. Element. Sch. J. 100: 3-17.

Astin, A. W., and Nichols, R. C. (1964). Life goals and vocational choice. J. Appl. Psychol. 48: $50-58$.

Atkinson, J. W. (1974). The mainsprings of achievement oriented activity. In Atkinson, J. W., and Raynor, J. O. (eds.), Motivation and Achievement, Winston, Washington, DC, pp. 108-120.

Bandura, A. (1986). Social Foundations of Thought and Action: A Social Cognitive Theory, Prentice Hall, Englewood Cliffs, NJ.

Catsambis, S. (1995). Gender, race, ethnicity, and science education in the middle grades. J. Res. Sci. Teach. 32: 243-257.

Cross, S., and Markus, H. (1994). Self-schemas and competent performance. J. Educ. Psychol. 86: 423-438.

Day, J. D., Borkowski, J. G., Punzo, D., and Howsepian, B. (1994). Enhancing possible selves in Mexican American students. Motiv. Emotion 18: 79-93.

DeBacker, T. K., and Nelson, R. M. (1999). Variations on an expectancy-value model in science. Contemp. Educ. Psychol. 24(2): 71-94.

DeBacker, T. K., and Nelson, R. M. (2000). Motivation to learn science: Differences related to gender, class type, and ability level. J. Educ. Res. 93(4): 245-254.

Dweck, C. S., and Bush, E. (1976). Sex differences in learned helplessness: Differential debilitation with peer and adult evaluations. Dev. Psychol. 12: 147-156.

Dweck, C. S., and Gilliard, D. (1975). Expectancy statements as determinants of reactions to failure: Sex differences in persistence and expectancy changes. J. Pers. Soc. Psychol. 32: 1077-1084.

Eccles, J. S. (1984). Sex differences in achievement patterns. In Sondereggar, T. (ed.), Nebraska Symposium on Motivation, Vol. 32, University of Nebraska Press, Lincoln, NE, pp. 97132.

Eccles, J. S. (1987). Gender roles and women's achievement-related decisions. Psychol. Women Q. 11: 135-172.

Eccles, J. S., Adler, T. F., Futterman, R., Goff, S. B., Kaczala, C. M., Meece, J. L., and Midgley, C. (1983). Expectancies, values and academic behaviors. In Spence, J. T. (ed.), Achievement and Achievement Motives, W.H. Freemen, San Francisco, CA, 75-146.

Eccles, J. S., Jacobs, J. E., and Harold, R. D. (1990). Gender role stereotypes, expectancy effects, and parents' socialization of gender differences. J. Soc. Issu. 46(2): 183-201.

Eccles, J. S., and Wigfield, A. (1995). In the mind of the actor: The structure of adolescents' achievement task values and expectancy-related beliefs. Soc. Pers. Soc. Psychol. Bull. 21: 215-225.

Eccles, J. S., Wigfield, A., Harold, R. D., and Blumenfeld, P. (1993). Age and gender differences in children's self and task perceptions during elementary school. Child Dev. 64: 830-847. 
Feather, N. T. (1988). Values, valences, and course enrollment: Testing the role of personal values within an expectancy-valence framework. J. Educ. Psychol. 80: 381-391.

Fennema, E., and Sherman, J. (1977). Sex-related differences in mathematics achievement, spatial visualization and affective factors. Am. Educ. Res. J. 14: 51-71.

Fennema, E., and Sherman, J. (1978). Sex-related differences in mathematics achievement and related factors: A further study. J.Res. Math. Educ. 9: 189-203.

Fiorentine, R. (1988). Increasing similarity in the values and life plans of male and female college students? Evidence and implications. Sex Roles 18: 143-158.

Frieze, I. H., Fisher, B., Hanusa, M., and Valle, V. (1978). Attributing the causes of success and failure: Internal and external barriers to achievement in women. In Sherman, J., and Denmark, F. (eds.), Psychology of Women: Future Directions of Research, Psychological Dimensions, New York, pp. 519-552.

Gjesme, T. (1979). Future time orientation as a function of achievement motives, ability, delay of gratification, and sex. J. Psychol. 101: 173-188.

Gjesme, T. (1981a). Is there any future in achievement motivation? Motiv. Emotion 5: 115-138.

Gjesme, T. (1981b). Some factors influencing perceived goal distance in time: A preliminary check. Percept. Mot. Skills 53: 175-182.

Gjesme, T. (1983a). Motivation to approach success $\left(\mathrm{T}_{\mathrm{s}}\right)$ and motivation to avoid failure $\left(\mathrm{T}_{\mathrm{f}}\right)$. Scan. J. Educ. Res. 27: 145-164.

Gjesme, T. (1983b). Worry and emotionality components of test anxiety in relation to situational and personality determinants. Psychol. Rep. 52: 267-280.

Gjesme, T. (1996). Future time orientation and motivation. In Gjesme, T., and Nygard, R. (eds.), Advances in Motivation and Emotion, Scandinavian University Press, Cambridge, MA, pp. 210-222.

Greene, A. L. (1990). Great expectations: Constructions of the life course during adolescence. J. Youth Adolesc. 19: 289-306.

Greene, A. L., and Wheatley, S. M. (1992). "I've got a lot to do and I don't think I'll have the time": Gender differences in late adolescents' narratives of the future. J. Youth Adolesc. 21: 667-686.

Greene, B. A., DeBacker, T. K., Ravindran, B., and Krows, A. J. (1999). Goals, values, and beliefs as predictors of achievement and effort in high school mathematics classes. Sex Roles 40: 421-458.

Greenfield, T. A. (1997). Gender- and grade-level differences in science interest and participation. Sci. Educ. 81: 259-277.

Halvari, H. (1991). Goal distance in time and its effects on the relations between achievement motives, future-time orientation, and motor performance among girls and boys. Percept. Mot. Skills 72: 675-697.

Halvari, H., and Thomassen, T. O. (1997). Achievement motivation, sports-related future orientation, and sporting career. Genet., Soc., Gen. Psychol. Monogr. 123: 343-365.

Horner, M. S. (1974). The measurement and behavioral implications of fear of success in women. In Atkinson, J. W., and Raynor, J. O. (eds.), Motivation and Achievement, Winston, Washington, DC, pp. 188-196.

Husman, J., and Lens, W. (1999). The role of the future in student motivation. Educ. Psychol. 34: 113-125.

Kahle, J. B., and Lakes, M. K. (1983). The myth of equality in science classrooms. J. Res. Sci. Teach. 20: 131-140.

Kahle, J. B., Parker, L. H., Rennie, L. J., and Riley, D. (1993). The myth of equality in science classrooms. Educ. Psychol. 28: 379-404.

Kao, G. (2000). Group images and possible selves among adolescents: Linking stereotypes to expectations by race and ethnicity. Sociol. Forum 15: 407-430.

Kimball, M. M. (1989). A new perspective on women's math achievement. Psychol. Bull. 105(2): 198-214.

Knox, M., Funk, J., Elliott, R., and Bush, E. G. (2000). Gender differences in adolescents' possible selves. Youth Soc. 31: 287-309.

Lamm, H., Schmidt, R. W., and Tromsdorff, G. (1976). Sex and social class as determinants of future orientation (time perspective) in adolescents. J. Pers. Soc. Psychol. 34: 317-326. 
Lee, V. E., and Burkam, D. T. (1996). Gender differences in middle grade science achievement: Subject domain, ability level, and course emphasis. Sci. Educ. 80(6): 613-650.

Lens, W., Simons, J., and Dewitte, S. (2001). Student motivation and self-regulation as a function of future time perspective and perceived instrumentality. In Volet, S., and Jarvela, S. (eds.), Motivation in Learning Contexts: Theoretical Advances and Methodological Implications, Pergamon, Amersterdam, New York, pp. 233-248.

Lesser, G. S., Krawitz, R. N., and Packard, R. E. (1963). Experimental arousal of achievement motivation in adolescent girls. J. Abnorm. Soc. Psychol. 66: 59-66.

Lips, H. M. (1995). Through the lens of mathematical/scientific self-schemas: Images of students' current and possible selves. J. Appl. Soc. Psychol. 25: 1671-1700.

Manderlink, G., and Harackiewicz, J. H. (1984). Proximal versus distal goal setting and intrinsic motivation. J. Pers. Soc. Psychol. 47: 918-928.

Marcus, H., and Nurius, P. (1986). Possible selves. Am. Psychol. 41: 954-969.

Meece, J. L., Wigfield, A., and Eccles, J. S. (1990). Predictors of math anxiety and its consequences for young adolescents' course enrollment intentions and performance in mathematics. J. Educ. Psychol. 82: 60-70.

Miller, R. B., and Brickman, S. J. (2001). A model of future-oriented motivation and selfregulation. Paper Presented at the American Psychological Association Annual Conference, San Francisco, CA.

Miller, R. B., and Brickman, S. J. (2004). A model of future-oriented motivation and selfregulation. Educ. Psychol. Rev. 16: 9-33.

Miller, R. B., DeBacker, T. K., and Greene, B. A. (1999). Perceived instrumentality and academics: The link to task valuing. J. Instr. Psychol. 26: 250-260.

Miller, R. B., Greene, B. A., Montalvo, G. P., Ravindran, B., and Nichols, J. D. (1996). Engagement in academic work: The role of learning goals, future consequences, pleasing others and perceived ability. Contemp. Educ. Psychol. 21: 388-422.

Nolen, S. B., and Haladyna, T. M. (1990). Motivation and studying in high school science. J. Res. Sci. Teach. 27(2): 115-126.

Nurmi, J.-E. (1987). Age, sex, social class, and quality of family interactions as determinants of adolescents' future orientation: A developmental task interpretation. Adolescence 23(88): 977-991.

Nurmi, J.-E. (1991). How do adolescents see their future? A review of the development of future orientation and planning. Dev. Rev. 11: 1-59.

Nurmi, J.-E., Poole, M. E., and Kalakoski, V. (1994). Age differences in adolescent futureoriented goals, concerns, and related temporal extension in different sociocultural contexts. J. Youth Adolesc. 23: 471-487.

Nurmi, J.-E., Poole, M. E., and Seginer, R. (1995). Tracks and transitions-A comparison of adolescent future-oriented goals, explorations, and commitments in Australia, Israel, and Finland. Int. J. Psychol. 30: 355-375.

Nurmi, J.-E., and Pulliainen, H. (1991). The changing parent-child relationship, self-esteem, and intelligence as determinants of orientation to the future during early adolescence. $J$. Adolesc. 14: 35-51.

Nurmi, J.-E., and Salmela-Aro, K. (2002). Goal construction, reconstructions, and depressive symptoms in a lifespan context: The transition from school to work. J. Pers. 70: 385420.

Nuttin, J. (1985). Future Time Perspective and Motivation: Theory and Research Method, Erlbaum, Hillsdale, NJ.

Pajares, F. (1996). Self-efficacy beliefs and mathematical problem-solving. Contemp. Educ. Psychol. 21: 325-344.

Parsons, J. E., and Ruble, D. N. (1977). The development of achievement-related expectancies. Child Dev. 48: 1075-1079.

Raynor, J. O. (1970). Relationships between achievement-related motives, future orientation, and academic performance. J. Pers. Soc. Psychol. 15: 28-33.

Raynor, J. O., and Entin, E. E. (1982). Theory and research on future orientation and achievement motivation. In Raynor, J. O., and Entin, E. E. (eds.), Motivation, Career Striving, and Aging, Hemisphere, New York, pp. 13-82. 
Ruvolo, A. P., and Markus, H. R. (1992). Possible selves and performance: The power of selfrelevant imagery. Soc. Cogn. 10: 95-124.

Schunk, D. H. (1989). Self-efficacy and cognitive skill learning. In Ames, C., and Ames, R. (eds.), Research on Motivation in Education. Vol 3: Goals and Cognitions, Academic Press, San Diego, CA, pp. 13-44.

Segal, H. G., DeMeis, D. K., Wood, G. A., and Smith, H. L. (2001). Assessing future possible selves by gender and socioeconomic status using the Anticipated Life History Measure. $J$. Pers. 69: 57-87.

Seginer, R. (1988). Adolescents' orientation toward the future: Sex role differentiation in a sociocultural context. Sex Roles 18: 739-757.

Seginer, R. (2000). Defensive pessimism and optimism correlates of adolescent future orientation: A domain-specific analysis. J. Adolesc. Res. 15: 307-326.

Seginer, R., and Halabi-Kheir, H. (1998). Adolescents' passage to adulthood: Future orientation in the context of culture, age, and gender. Int. J. Intercult. Relat. 22: 309-328.

Simpson, R. D., and Oliver, J. S. (1990). A summary of major influences on attitude toward and achievement in science among adolescent students. Sci. Educ. 74: 1-18.

Steinkamp, M. W., and Maehr, M. L. (1984). Gender differences in motivational orientations toward achievement in school science: A quantitative synthesis. Am. Educ. Res. J. 21:39-59.

Sullins, E. S., Hernandez, D., Fuller, C., and Tashiro, J. S. (1995). Predicting who will major in a science discipline: Expectancy-value theory as part of an ecological model for studying academic communities. J. Res. Sci. Teach. 32(1): 99-119.

Sundberg, N. D., Poole, M. E., and Tyler, L. E. (1983). Adolescents' expectations of future events-A cross-cultural study of Australians, Americans, and Indians. Int. J. Psychol. 18: 415-427.

Thomassen, T. O., and Halvari, H. (1996). Achievement motivation and involvement in sport competitions. Percept. Mot. Skills 83: 1363-1374.

Van Calster, K., Lens, W., and Nuttin, J. R. (1987). Affective attitude toward the personal future: Impact on motivation in high school boys. Am. J. Psychol. 100(1): 1-13.

Weinburg, M. (1995). Gender differences in student attitudes toward science: A meta-analysis of the literature from 1970 to 1991. J. Res. Sci. Teach. 32(4): 387-398.

Wigfield, A. (1994). Expectancy-value theory of achievement motivation: A developmental perspective. Educ. Psychol. Rev. 6: 49-78.

Wigfield, A., and Eccles, J. S. (1992). The development of achievement task values: A theoretical analysis. Dev. Rev. 12: 265-310.

Wigfield, A., and Eccles, J. S. (2002). The development of competence beliefs expectancies for success, and achievement values from childhood through adolescence. In Wigfield, A., and Eccles, J. S. (eds.), Development of Achievement Motivation, Academic Press, Orlando, FL, pp. $92-122$.

Wigfield, A., Eccles, J. S., MacIver, D., Reuman, D., and Midgley, C. (1991). Transitions at early adolescence: Changes in children's domain-specific self-perceptions and general selfesteem across the transition to junior high school. Dev. Psychol. 27: 552-565.

Wigfield, A., Eccles, J. S., Yoon, K. S., Harold, R. D., Arbreton, A. J. A., Freedman-Doan, C., and Blumenfeld, P. C. (1997). Change in children's competence beliefs and subjective task values across the elementary school years: A three-year study. J. Educ. Psychol. 89(3): 451-469.

Zaleski, Z. (1987). Behavioral effects of self-set goals for different time ranges. Int. J. Psychol. 22: $17-38$. 
Copyright of Educational Psychology Review is the property of Kluwer Academic Publishing and its content may not be copied or emailed to multiple sites or posted to a listserv without the copyright holder's express written permission. However, users may print, download, or email articles for individual use. 